\title{
Increased rate of depression and psychosomatic symptoms in Jewish migrants from the post-Soviet-Union to Germany in the 3rd generation after the Shoa
}

\author{
E Ullmann ${ }^{1}$, A Barthel ${ }^{2,3}$, J Licinio $^{4}, \mathrm{~K}$ Petrowski ${ }^{5}$, SR Bornstein ${ }^{2}$ and B Strau ${ }^{1}$
}

The mental health status of persons with Jewish background living in Germany is discussed with special regard to social exclusion like anti-Semitism and overprotective parental rearing behavior, as a transmissional factor of the KZ-Syndrome. These stressors are considered in the context of a higher risk for depression/fear and psychosomatic disorders and also abnormal cortisol levels. The present sample $(\mathrm{N}=89)$ is derived from the Jewish population currently living in the German region of Saxony aged between 17-36 years that emigrated from the post-Soviet-Union areas. The mean age was 22.9 years. Two questionnaires to detect psychosomatic symptoms (Giessen complaint list (GBB)-24, hospital anxiety and depression scale) and one questionnaire addressing parental rearing behavior (FEE) were employed. Comparisons were drawn with normative data from the literature about the German residential population. In addition, questions were asked concerning the experience of antiSemitism in Germany and in the post-Soviet-Union areas. A higher prevalence of depression/fear (10.3\% versus $18.2 \%)$ and psychosomatic symptoms ( $M=14.03$ versus $17.8 ; t=2.42 ; P<0.05)$ was observed in Jewish migrants to Germany as compared with non-Jewish German residents. Furthermore, anti-Semitic experiences in Germany correlated positively with depression $(r=0.293 ; P<0.01)$ and fear $(r=0.254 ; P<0.05)$. The anti-Semitic experiences in the post-Soviet-Union areas also correlated positively with limb pain $(r=0.41, P<0.01)$, fatigue symptoms $(r=0.296, P<0.01)$ and psychocardial symptoms $(r=0.219$, $P<0.05$ ). It was also confirmed that the male respondents recalled a controlling and overprotecting maternal rearing behavior more frequently than the German standard random sample $(M=15.39$ versus $18.6 ; t=2.68 ; P<0.01)$. The latter also correlated significantly positive with epigastric pain $(r=0.349 ; P<0.01)$. The present results show that depression, fear and psychosomatic problems are common in Jewish residents with a background of migration from the post-Soviet-Union areas to Germany. Apart from the transgenerational passing of psychological traumata and the Holocaust experiences, other stressors like anti-Semitism, control and overprotection as parental rearing measures appear to be important factors specifically contributing to the pathogenesis of the attributed symptoms.

Translational Psychiatry (2013) 3, e241; doi:10.1038/tp.2013.17; published online 12 March 2013

\section{Introduction}

Violence and harm resulting in psychological traumatization is often not only restricted to the individual itself but may also frequently affect his family and close relatives. In the present study, we therefore examined the question whether familial experiences of the Shoa, ${ }^{1,2}$ emigration $^{3-5}$ and social exclusion $^{6}$ among Jewish migrants from the post-Soviet-Union areas, with special regard to multiple accumulative traumatization and retraumatization ${ }^{7}$ coincide with specific alterations of the mental health status.

Increased psychosocial stress and the associated persistent hypercortisolism due to an increased activation of the adrenocortical axis may result in various metabolic disorders.
For example, elevated cortisol levels among Jewish migrants have been described. ${ }^{8}$ Furthermore, specific stress-related changes of neuronal structure and activity, for example a diminished hippocampal capacity ${ }^{9}$ as well as smaller bilateral hippocampal volume ${ }^{10}$ among patients who were diagnosed with post traumatic stress disorders have been discussed. ${ }^{11}$

The recent prognosis of the $\mathrm{WHO}^{12}$ with regard to the increasing prevalence of depressive disorders demonstrates the relevance of research on individuals with a higher psychosomatic vulnerability. Our study therefore examined the following three factors potentially affecting the psychosomatic susceptibility of people with Jewish background:

\footnotetext{
${ }^{1}$ Institute of Psychosocial Medicine and Psychotherapy University Hospital, Jena, Germany; ${ }^{2}$ Department of Medicine, University of Dresden, Carl Gustav Carus, Dresden, Germany; ${ }^{3}$ Endokrinologikum RUHR, Bochum, Germany; ${ }^{4}$ Center for Pharmacogenomics and Clinical Pharmacology, Semel Institute for Neuroscience and Human Behavior, David Geffen School of Medicine at University of California, Los Angeles, CA, USA and ${ }^{5}$ Dresden University of Technology, Department of Psychotherapy and Psychosomatic Medicine, Dresden, Germany

Correspondence: Dr E Ullmann, Department of Child and Adolescent Psychiatry and Psychotherapy, University Hospital, Friedrich-Schiller-University Jena, Am Steiger 6, 07743 Jena, Germany.

E-mail: enrico.ullmann@med.uni-jena.de

Keywords: anti-Semitism; depression; Holocaust; intergenerational transmission of trauma; psychosomatic symptoms; recalled parental rearing behavior

Received 24 September 2012; accepted 2 Decemeber 2012
} 
1. Emigration: Among different groups of migrants an increased prevalence for specific symptoms has been documented. $^{3-5}$ For example, Russian-speaking immigrants with German family background have been reported to have a higher prevalence of psychosomatic disorders ${ }^{13}$ and an increased anxiety-score has been found in Jewish migrants to Germany. ${ }^{8}$

2. Holocaust and its familial aftermath: Several authors associate Jewish experiences of the Holocaust and their passing on within the family with increased psychosomatic susceptibility $^{1,2,7,14-18}$ In this context, the assumptions of Levine ${ }^{1}$ and $\mathrm{Kogan}^{2}$ reporting overprotective parental rearing behavior as a potential obstacle for the development of the children's identity are of special importance for this study.

3. Anti-Semitism as a factor of social exclusion: Recent studies showed an increase of anti-Semitism in Germany. ${ }^{19,20}$ Social exclusion is regarded as a determinant for several health problems, in particular cardiovascular diseases (ICD-9 390-459). ${ }^{21}$

\section{Materials and methods}

The collection of data was carried out between December 2009 and August 2010. Within one population each subject was polled once. The subjects were sampled through records of the three Saxon urban communities in Dresden, Leipzig and Chemnitz. We recruited families who immigrated since 1992 from the post-Soviet-Union-areas to Saxony in Germany. Subjects with grandparents born after January 1st 1946 and subjects with parents born earlier than December 31st 1946, were excluded from the prospective subject group. Also mentally retarded people were excluded from the study.

Beforehand, a population of $\mathrm{N}=252$ in Saxony was determined. These persons were handed out established validated questionnaires (hospital anxiety and depression scale, Giessen complaint list (GBB)-24 and questionnaire of recalled parental rearing behavior) and also self-designed questions in order to determine anti-Semitic experiences. Eventually, data of 89 subjects could be used for the study. The sociodemographic characteristics of the population are shown in Table 1.

Anxiety and depression were captured with the hospital anxiety and depression scale. The hospital anxiety and depression scale is a 14-item, self-administered rating scale designed to measure symptoms of anxiety and depression. The respective subscales are generated from seven items each. Higher scores indicate higher levels of anxiety or depression. A cutoff value of $8 / 9$ is regarded as indicating significant depression, and a cutoff value of $10 / 11$ is indicative of anxiety. Normative data from the German residential population $^{22}$ was used to interpret our results.

Acute episodes of cardiac-related symptoms, fatigue, epigastric pain and back complaints were captured by the short form of the Giessen complaint list (GBB-24). It comprises of 24 items, which are defined into four subscales, each including six items with ratings from $0-4$. For interpretation, again the normative data from the German residential population $^{23}$ was drawn from the literature. Also, normative data concerning Russian late repatriates ${ }^{13}$ was available.

Furthermore, parental rearing behavior was documented by use of the questionnaire of recalled parental rearing behavior.
Table 1 Sociodemographic characteristics of the population

\begin{tabular}{|c|c|}
\hline \multicolumn{2}{|l|}{ Age } \\
\hline Mean & 22.94 (s.d. 4.05) \\
\hline Range & $17-36$ \\
\hline Missing & 1 \\
\hline \multicolumn{2}{|l|}{ Sex } \\
\hline Male & $44(49.4 \%)$ \\
\hline Female & $42(47.2 \%)$ \\
\hline Missing & $3(3.4 \%)$ \\
\hline \multicolumn{2}{|l|}{ Partner } \\
\hline Yes & $27(30.3 \%)$ \\
\hline No & $62(69.7 \%)$ \\
\hline \multicolumn{2}{|l|}{ Education } \\
\hline Without a graduate degree & $2(2.2 \%)$ \\
\hline Secondary modern school & $1(3.4 \%)$ \\
\hline Secondary school certificate & $23(25.8 \%)$ \\
\hline Mature professional school & $7(7.9 \%)$ \\
\hline High school & $41(46.1 \%)$ \\
\hline Apprenticeship & $4(4.5 \%)$ \\
\hline University/college & $11(12.4 \%)$ \\
\hline \multicolumn{2}{|l|}{ Bottom line per month } \\
\hline$<500 €$ & $55(67.1 \%)$ \\
\hline to $1.000 €$ & $20(24.4 \%)$ \\
\hline to $2.000 €$ & $5(6.1 \%)$ \\
\hline to $3.000 €$ & $2(2.4 \%)$ \\
\hline
\end{tabular}

The questionnaire of recalled parental rearing behavior is conceptually based on the swedish EMBU instrument, which is one of the most commonly used tests for various psychopathological conditions. The questionnaire of recalled parental rearing behavior allows the assessment of memories of perceived parental rearing behavior separately for the father and mother. It comprises factor-analytically derived dimensions of (a) rejection and punishment, (b) emotional warmth and (c) control and overprotection. To interpret this self-administered rating scale with 24 items, we used German normative data for maternal as well as paternal rearing behavior. $^{24}$

Moreover, we included questions to measure anti-Semitic experiences of the subject group in order to test their association with the quoted complaints. We asked separately for experiences in the country of origin and Germany. These two items with ratings from 0-4 were captured in their expression and were processed statistically.

\section{Results}

Our data shows that individuals with Jewish background in Germany have a higher prevalence for anxiety and depression $(7.9 \%)$ as compared with the German residential population. As shown in Figure 1, the difference in mean for depression was significant in comparison to non-Jewish German residents of the same age $(M=2.9$ versus 4.45; $P<0.01)$. Furthermore, we could demonstrate that the mean score for psychosomatic symptoms was significantly increased in comparison to the normative data of older people (14.03 (95\% confidence interval $=13.5-14.56)$ versus 17.8 $(95 \%$ confidence interval $=14.79-20.8))$. After adjustment for age and gender differences, the following specific symptoms showed a significantly higher prevalence in the female 
population with Jewish background: attacks of psychocardial symptoms (for example, palpitations or stabbing pain in the chest) $(M=1.94$, s.d. $=3$ versus $M=3.10$, s.d. $=3.45$; $P<0.05)$, limb pain $(\mathrm{M}=4.46$, s.d. $=4.2$ versus $\mathrm{M}=7.29$, s.d. $=4.89 ; P<0.01)$ and fatigue $(M=4.03$, s.d. $=4.3$ versus $\mathrm{M}=6.50$, s.d. $=5.32 ; P<0.01$ ) (Figure 2). In contrast, in male individuals, the rate of fatigue $(M=2.86$, s.d. $=3.44$ versus $\mathrm{M}=5.11$, s.d. $=5.43 ; P<0.05)$ and $\operatorname{limb}$ pain $(\mathrm{M}=3.53$, s.d. $=3.74$ versus $\mathrm{M}=5.23$, s.d. $=4.13 ; \quad P<0.05$ ) were significantly increased in the population with Jewish

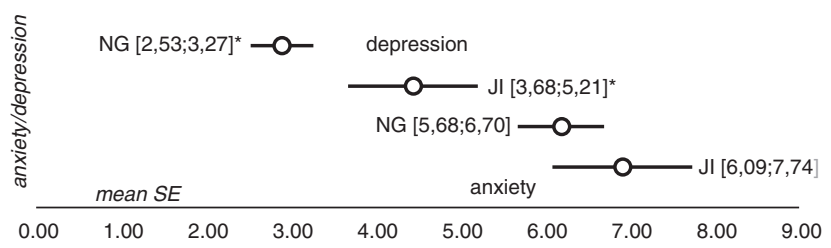

Figure 1 Mean values of depression and anxiety in immigrants with Jewish family background ( $\mathrm{Jl}, \mathrm{N}=85$ ) as compared with native German subjects (NG, $\mathrm{N}=136$ ). Data is expressed as means \pm s.e.; ${ }^{*} P=1 \%$.

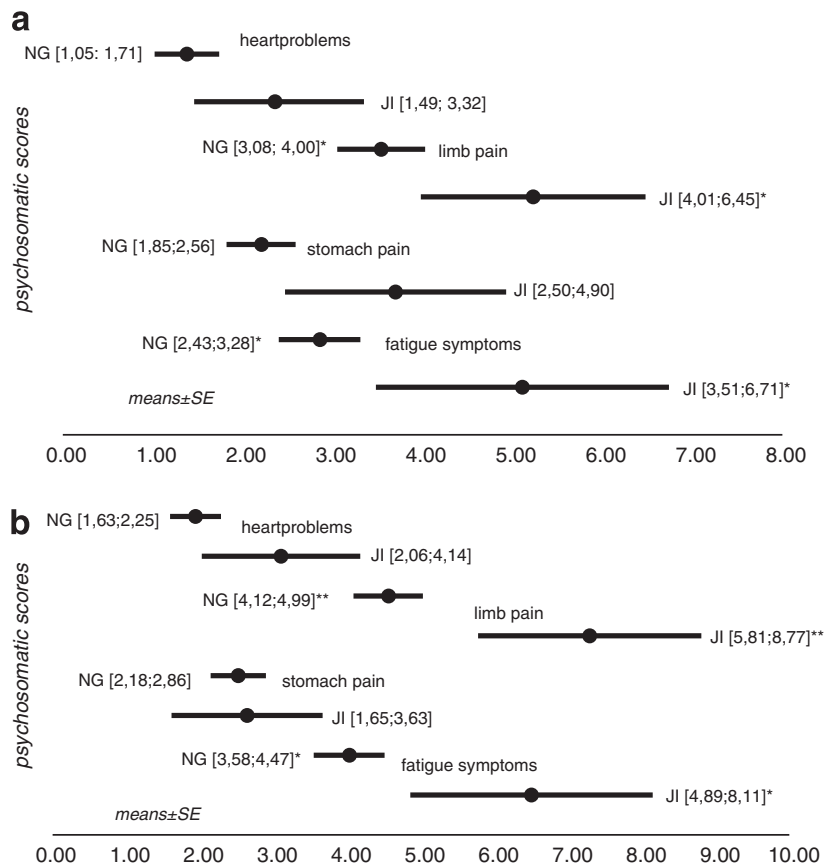

Figure 2 Mean values of psychosomatic symptoms in (a) male immigrants with Jewish family background ( $\mathrm{Jl}, \mathrm{N}=44)$ as compared with native German subjects ( $N G, N=252)$ and (b) female individuals ( $\mathrm{JI}, \mathrm{N}=42 ; \mathrm{NG}, \mathrm{N}=356$ ). Data is expressed as means \pm s.e.; ${ }^{*} P=5 \%,{ }^{* *} P=1 \%$. background. Finally, Jewish male individuals remembered overprotective maternal rearing behavior more often than the control group $(M=15.39$, s.d. $=3.81$ versus $M=18.6$, s.d. =4.58; $P<0.01$; Table 2). To quantify the associations of the factors studied, we finally calculated pearson- and spearman-correlations (Table 3).

\section{Discussion}

Our results show increased scores for depression, acute psychocardial problems, fatigue symptoms and limb pain among young Jewish people. For older Jewish migrants in Germany, another study observed an increased anxiety score. ${ }^{8}$ Russian-speaking immigrants with a German family background reportedly had elevated scores for headaches, lassitude, fatigue and feeling of weakness. ${ }^{13}$ On the basis of these results, it has to be discussed whether acculturation stress, as mentioned by Wittig et al., ${ }^{13}$ shows an association to paroxysmal psychocardial symptoms that frequently occurred in female Jewish individuals in this study. However, the significantly increased rate of depression and cardiac symptoms may indicate an elevation of stress hormones. Coherences between depression and increased cortisol-levels ${ }^{25,26}$ were occupied and should also be examined within the group of third generation Jewish migrants after the Shoa, not least because of the predicted increase of depressive disorders. ${ }^{12}$

Table 3 Spearman's rank correlation coefficient between GBB-24/hospital anxiety and depression scale-D and anti-Semitic experiences, and Pearson product moment correlation coefficient between parental rearing measures and GBB-24/hospital anxiety and depression scale-D

\begin{tabular}{|c|c|c|c|c|}
\hline \multirow[b]{2}{*}{$\begin{array}{l}\text { Psychosomatic } \\
\text { scores GBB-24 }\end{array}$} & \multicolumn{2}{|l|}{$\begin{array}{l}\text { Anti-Semitic } \\
\text { experiences }\end{array}$} & \multicolumn{2}{|c|}{ Parental rearing measures } \\
\hline & $\begin{array}{c}\text { In post- } \\
\text { Soviet- } \\
\text { Union areas } \\
(r)\end{array}$ & $\stackrel{\ln }{\text { Germany }}$ & $\begin{array}{c}\text { Control and } \\
\text { overprotection } \\
\text { by mother }\end{array}$ & $\begin{array}{l}\text { Control and } \\
\text { overprotection } \\
\text { by father }\end{array}$ \\
\hline $\begin{array}{l}\text { Fatigue } \\
\text { symptoms }\end{array}$ & $0.296^{\star *}$ & 0.066 & 0.152 & 0.017 \\
\hline Stomach pain & 0.209 & 0.193 & $0.349^{\star *}$ & $0.323^{\star *}$ \\
\hline Limb pain & $0.410^{* *}$ & 0.041 & 0.013 & -0.032 \\
\hline Heart problems & $0.219^{*}$ & 0.155 & 0.047 & 0.064 \\
\hline HADS-D scores & & & & \\
\hline Anxiety & 0.098 & $0.254^{*}$ & 0.032 & -0.002 \\
\hline Depression & 0.203 & $0.293^{\star \star}$ & 0.076 & -0.032 \\
\hline
\end{tabular}

Abbreviation: HADS-D, hospital anxiety and depression scale-D.

${ }^{\star} P<0.05 ;{ }^{\star \star} P<0.01$ (two sided); $71 \leq \mathrm{N} \leq 89 ;(0.1<\mathrm{r}<0.3=$ small correlation, $0.3<\mathrm{r}<0.5=$ mediocre correlation, $r>0.5=$ high correlation).

Table 2 Differences between mean values for the parenteral control and overprotection in comparison to German normative data were tested for statistical significance by analysis of the Welch's $t$-test

\begin{tabular}{|c|c|c|c|c|c|c|c|c|c|c|c|c|}
\hline \multirow[t]{2}{*}{ Parental rearing measures } & \multicolumn{3}{|c|}{$\begin{array}{c}\text { Jewish female individuals, } \\
\text { age: } 17-36 \text { years }\end{array}$} & \multicolumn{3}{|c|}{$\begin{array}{l}\text { Normative data }{ }^{24} \text { age: } \\
18-35 \text { years }\end{array}$} & \multicolumn{3}{|c|}{$\begin{array}{l}\text { Jewish male individuals, } \\
\text { age: } 17-36 \text { years }\end{array}$} & \multicolumn{3}{|c|}{$\begin{array}{c}\text { Normative data }{ }^{24} \text { age: } \\
\text { 18-35 years }\end{array}$} \\
\hline & $\mathrm{N}$ & Mean & s.d. & $\mathrm{N}$ & Mean & s.d. & $\mathrm{N}$ & Mean & s.d. & $\mathrm{N}$ & Mean & s.d. \\
\hline Control and overprotection by mother & \multicolumn{6}{|c|}{$t(0.95 ; 43)=2.02 ; \mathrm{T}=1.04$} & \multicolumn{6}{|c|}{$t(0.99 ; 47)=2.68 ; T=4.38$} \\
\hline Control and overprotection by father & 34 & $\begin{array}{r}13.35 \\
t(0\end{array}$ & $\begin{array}{l}3.77 \\
38)=2\end{array}$ & $\begin{array}{l}511 \\
2 ; \mathrm{T}=\end{array}$ & 51 & 4 & 38 & $\begin{array}{r}16.16 \\
t(0\end{array}$ & $\begin{array}{l}4.07 \\
; 44)=\end{array}$ & $\begin{array}{r}369 \\
2 ; \mathrm{T}=\end{array}$ & $\begin{array}{l}14.78 \\
99\end{array}$ & 3.91 \\
\hline
\end{tabular}


Furthermore, we could provide evidence to some extent for the theories of Levine ${ }^{1}$ and Kogan. ${ }^{2}$ In the context of the children-of-survivors-complex, Levine ${ }^{1}$ describes parental rearing behavior like overprotection and interference with infantile individuation. Moreover, Levine ${ }^{1}$ states a lack of knowledge of children concerning their parent's experiences of the Holocaust and identification with parental characteristic features.

Kogan $^{2}$ illustrates coherences mainly influenced by parental activity. Parents tend to unconsciously force their children into roles and constellations that are traumatizing.

At least the male respondents perceived the maternal rearing behavior as overprotecting. We could also validate that overprotectional behavior as a potential obstacle to the child's individual evolvement is associated with sensation of epigastric pain. This is interesting, because this empirical evidence has not been described specifically in the literature so far. It cannot be precluded that within the subject group familial rearing measures that were passed on through the generations may influence gastro-intestinal complaints, which are not typical migration-associated complaints. This recalled parental rearing behavior could be induced by stereotypical gender roles, as male individuals are frequently raised more oriented towards performance due to increasing economic compulsions. Furthermore, this could be potentially attributed to moderated, but still existing paternal traditions. However, the effect of stress on the gastro-intestinal tract and respective psychosomatic symptoms has been sufficiently documented in the literature. ${ }^{27,28}$ Finally, our data provides evidence for the assumption that social exclusion caused by anti-Semitic experiences is associated with an elevated psychosomatic susceptibility. Again, of particular interest are the depressive symptoms, which may be potentially related to increasing antiSemitism in Germany. ${ }^{19,20}$

On the basis of the cumulative character of traumatizing experiences among migrants with Jewish background in the third generation after the Shoa to Germany, our present results can be considered as an indicator for additional stress fostering circumstances in this population, resulting in an elevated psychosomatic vulnerability. As a clinical implication of this specific situation it can also be expected that migrants with Jewish background in Germany are more prone for other stress-related diseases in addition to psychosomatic disorders. It has to be concluded that sensitive recognition of current developments and adequate prevention is required mandatory.

\section{Conflict of interest}

All authors declare that there is no conflict of interest to disclose.

Acknowledgements. There were no commercial sources of support.

1. Levine HB. Toward a psychoanalytic understanding of children of survivors of the Holocaust. Psychoanal Q 1982; 51: 70-92.

2. Kogan I. Enactment in the lives and treatment of Holocaust survivors' offspring. Psychoanal Q 2003; 71: 251-272.
3. Merbach M, Wittig U, Brähler E. Anxiety and depression by Polish and Vietnamese migrants in Leipzig depending on their adaptation process. Psychother Psychosom Med Psychol 2008; 58: 146-154.

4. Lindert J, Brähler E, Wittig U, Mielck A, Priebe S. Depression, anxiety and posttraumatic stress disorders in labor migrants, asylum seekers and refugees. A systematic overview. Psychother Psychosom Med Psychol 2008; 58: 109-122.

5. Bermejo I, Mayninger E, Kriston L, Härter M. Mental disorders in people with migration background compared with German general population. Psychiatrische Praxis 2010; 37: 225-232.

6. WHO a. Social Determinants of Health-The Solid Facts. 2nd Edition World Health Organization: Denmark, 2004

7. Keilson H. Sequential traumatization of children. Dan Med Bull 1980; 27: 235-237.

8. Korenblum W, Barthel A, Licinio J, Wong M-L, Wolf OT, Kirschbaum C et al. Elevated cortisol levels and increased rates of diabetes and mood symptoms in Soviet Union-born Jewish immigrants to Germany. Mol Psychiatry 2005; 10: 974-975.

9. Kitayama N, Vaccarino V, Kutner M, Weiss P, Bremner JD. 199. Magnetic resonance imaging (MRI) measurement of hippocampal volume in posttraumatic stress disorder: A meta-analysis. JAffect Disorders 1993; 88: 79-86.

10. Karl A, Schaefer M, Malta LS, Dörfel D, Rohleder N, Werner A. A metaanalysis of structural brain abnormalities in PTSD. Neurosci Biobehav Rev 2006; 30: 1004-1031.

11. Meewisse ML, Reitsma JB, De Vries GJ, Gersons BPR, Olff M. Cortisol and post-traumatic stress disorder in adults. Br J Psychiatry 2007; 191: 387-392.

12. WHO b. Global Burden of Disease. World Health Organization: Denmark, 2004.

13. Wittig U, Merbach M, Siefen RG, Brähler E. Complaints and health care system utilization of ethnic German migrants from the former Soviet Union to Germany and their families. Gesundheitswesen 2004; 66: 85-92.

14. Bergmann MS, Yucovy ME. Generations of The Holocaust. Columbia University Press: New York, 1982.

15. Kestenberg JS. Late sequelae in persecuted children. Psyche 1993; 8: 249-265.

16. Rosenthal G. The Holocaust in Three-Generations. Families of Victims and Perpetrators of the Nazi-Regime. Barbara Budrich: Opladen, Germany, 2010.

17. Fonagy $P$. The transgenerational transmission of holocaust trauma. Lessons learned from the analysis of an adolescent with obsessive-compulsive disorder. Attach Hum Dev 1999; 1: 92-114.

18. Niederland WG. The survivor syndrome: further observations and dimensions. J Am Psychoanal Assoc 1981; 29: 413-425.

19. Decker O, Weißmann M, Kiess J, Brähler E. Die Mitte in der Krise - Rechtsextreme Einstellungen in Deutschland 2010. Friedrich-Ebert-Stiftung: Berlin, Germany, 2010; http:// library.fes.de/pdf-files/do/07504-20120321.pdf.

20. Longerich $\mathrm{P}$, Heil J, Pfahl-Traughber A, Farschid O, Schoeps JH, Whadat-Hagh W et al. Antisemitismus in Deutschland-Erscheinungsformen, Bedingungen, Präventionsansätze. German Bundestag (Drs.17/7700): Berlin, Germany, 2011; http://dipbt.bundestag.de/ dip21/btd/17/077/1707700.pdf

21. Claussen B, Smith GD, Thelle D. Impact of childhood and adulthood socioeconomic position on cause specific mortality: The Oslo Mortality Study. J Epidemiol Community Health 2003; 57: 40-45.

22. Hermann-Lingen C, Buss U, Snaith RP. Hospitaly Anxiety and Depression Scale - German Version (HADS-D). Verlag Hans Huber: Bern, Switzerland, 2011.

23. Brähler E, Schumacher J, Brähler C. First all-Germany standardization of the brief form of the Giessen Complaints Questionnaire GBB-24. Psychother Psychosom Med Psychol 2000; 50: 14-21.

24. Schumacher J, Eisemann M, Brähler E. Fragebogen Zum Erinnerten Elterlichen Erziehungsverhalten. Hans Huber: Bern, Switzerland, 2000; http://www.psycontent.com/ content/x271850812557354/.

25. Burke HM, Davis MC, Otte C, Mohr DC. Depression and cortisol responses to psychological stress: a meta-analysis. Psychoneuroendocrinology 2005; 30 846-856.

26. Vreeburg SA, Hoogendijk WJG, van Pelt J, DeRijk RH, Verhagen JCM, van Dyck R et al. Major depressive disorder and hypothalamic-pituitary-adrenal axis activity. Arch Gen Psychiatry 2009; 66: 617-626.

27. Pauli $\mathrm{P}$, Herschbach $\mathrm{P}$, Weiner $\mathrm{H}$, von Rad M. Psychological factors of nonulcer dyspepsia Psychother Psychosom Med Psychol 1992; 42: 295-301.

28. Martinez SD, Malagon IB, Garewal HS, Cui H, Fass R. Non-erosive reflux disease (NERD)-acid reflux and symptom patterns. Aliment Pharmacol Ther 2003; 17 : $537-545$.

(c) $(-)$ Translational Psychiatry is an open-access journal published by Nature Publishing Group. This work is licensed under a Creative Commons Attribution-NonCommercialNoDerivs 3.0 Unported License. To view a copy of this license, visit http://creativecommons.org/licenses/by-nc-nd/3.0/ 